https://doi.org/10.36105/iut.2019n29.13

\title{
PRINCIPIO DE IMPARCIALIDAD COMO PRESUNCIÓN IURIS TANTUM EN LA PRUEBA PERICIAL CONTABLE EN MATERIA FISCAL
}

\section{PRINCIPLE OF IMPARTIALITY AS A PRESUMPTION IURIS TANTUM IN THE ACCOUNTING EXPERT EVIDENCE ON TAX MATTERS}

\author{
Edmundo Robledo Franco* \\ Investigador independiente, México \\ edmundorobledofranco@gmail.com
}

\section{RESUMEN:}

La prueba pericial contable en materia tributaria ha distorsionado su alcance al ser valorada por el intérprete de la norma dando pauta a un escenario de interpretación subjetivo y ambiguo, cuyo principal resultado es desestimar la información aportada al tema debatido a través de la misma. Los paradigmas de interpretación que se manifiestan alrededor de la valoración de esta prueba, han tomado un giro importante para ahora apreciar su contenido conforme a los principios ontológicos que la rigen, particularmente el principio de imparcialidad como presunción iuris tantum, dado que es a través de dichos principios que ahora se permite contrastar los argumentos que utilizan los juzgadores para desestimar un juicio de valoración respecto de la prueba concreta.

Palabras clave:

Prueba pericial contable, Derecho fiscal, Juicio de valoración.

\section{ABSTRACT:}

The tax auditing expert opinion has distorted its scope when assessed by the taxing judges giving guidelines to a subjective and ambiguous interpretation scenario whose principal result is to reject the information provided to the particular theme subject to debate. Interpretation paradigms that manifest around the evaluation of this test,

* Doctor en Derecho de la Empresa. Abogado Postulante. Miembro del Sistema Nacional de Investigadores del CONACYT. edmundorobledofranco@gmail.com. 
has taken an important turn of events to be now appreciated by its content, according to the ontological principles that govern it, particularly the principle of impartiality as a iuris tantum presumption, due to the fact that it is through these principles that nowadays provides the elements that allows to contrast the arguments that judges use to dismiss a judgment of valuation with respect to the concrete evidence.

\section{Keywords:}

Tax auditing expert opinion, taxing law, judgment of valuation.

\section{INTRODUCCIÓN}

El intérprete de la norma tributaria se enfrenta a un catálogo de paradigmas que se han ido formando a lo largo de una escuela de formación clásica, un sentido de interpretación restrictivo, un sentir jurídico partícipe de una interpretación pro persona ${ }^{1}$ o simplemente como un seguimiento más en la corriente de interpretación que se ha venido sosteniendo por diversos juzgadores.

Sin embargo, existen ocasiones en que esos paradigmas deben ser cuestionados con argumentos sólidos que permitan focalizar la perspectiva a partir de la cual se deben centralizar los argumentos jurídicos y la consecuente aplicación de la norma de fondo por aplicar, no solamente para otorgar un sentido o inclinación en favor de una pretensión deducida en juicio (pues lógico es que, aquella parte cuya pretensión no ha prevalecido sobre la de su contraria parte, éste sostendrá que se trató de una resolución injusta, o en el mejor de los casos, infundada), pero más allá de posturas subjetivas, el presente texto busca destacar cómo el propio interprete de la norma debe emitir un pronunciamiento investido de una auténtica técnica jurídica que limite todo espacio a la arbitrariedad en el pronunciamiento de la ley como norma jurídica individualizada (sentencia), al tiempo en que, se otorgue claridad al pronunciamiento de fondo y a la valoración de una prueba cuya esencia principal es la de dotar de elementos de convicción a la resolución de la cuestión debatida.

En el presente ensayo, se elabora un análisis de dicho mecanismo de valoración al tenor del principio de imparcialidad como presunción iuris tantum, con la intención de aportar una perspectiva unívoca que permita identificar con certeza las pautas de aplicación de este juicio valorativo concedido al intérprete de la norma fiscal que procure generar condiciones óptimas para reconducir una interdicción en la arbitrariedad.

Lo anterior, con la finalidad de conciliar la arraigada tradición del jurista mexicano de contemplar el citado principio en toda institución jurídica, evidenciando que este principio no solo concilia los nuevos mecanismos de concepción del derecho, sino también es compatible con las nuevas tendencias de solución de conflictos que surgen en materia tributaria ${ }^{2}$ y su interrelación con la práctica contable.

\footnotetext{
Este principio es también conocido como interpretación pro persona y fue introducido en nuestro sistema constitucional a partir de las reformas constitucionales efectuadas en junio de 2011 al artículo $1^{\circ}$ de la Constitución Política de los Estados Unidos Mexicanos. (Miranda Camarena \& Navarro Rodríguez, 2014).

2 Como resultado de la iniciativa presentada en el marco de la reforma fiscal del ejercicio 2013 se adicionó un capítulo segundo denominado "De los Acuerdos Conclusivos", en el Título III del Código Fiscal de la
} 
Así en el primer apartado habrán de desarrollarse de manera sucinta las nociones fundamentales de la problemática en general; en el segundo apartado se desarrolla la trascendencia de la determinación en la calificación de la pericial contable como medio probatorio eficaz en materia tributaria. En el tercer apartado se precisarán las consideraciones acerca del principio de imparcialidad del perito como presunción iuris tantum, para finalmente, hablar de las aportaciones conclusivas que el desarrollo de esta investigación sostiene.

\section{VALORACIÓN DE LA PRUEBA PERICIAL EN MATERIA CONTABLE: ¿FACULTAD OMNÍMODA?}

El intérprete de la norma tributaria se enfrenta a una especie de catálogo de paradigmas que "deben" aplicarse al momento en que realiza una función de interpretación de aquellas.

Sin embargo, muchos de esos modelos a seguir o pautas de interpretación provenientes del derecho común, han dejado de ser aplicables a los nuevos modelos de interpretación que se sostienen en el orden jurídico nacional como género, y más aún en el derecho tributario, como especie, por circunstancias tan precisas que se rigen dentro de la materia tributaria como lo puede ser el denominado principio de autonomía calificadora del derecho tributario, ${ }^{3}$ por virtud del cual este principio provee de un sentido propio a una norma tributaria en cuanto a definir conceptos, figuras e instituciones jurídicas, mismas que incluso pudieran resultar distintas o contrarias al significado del que gozarán las mismas en el Derecho común del que provengan.

Ante este escenario, las presentes líneas sirven para destacar la importancia que revisten en la creación, implementación y seguimiento de esos paradigmas, los principios ontológicos que rigen a la prueba per se, particularmente atendiendo al principio de imparcialidad como presunción Iuris Tantum en la prueba pericial contable en materia fiscal, ya que es a través de estos principios que se debe informar y delimitar el sentido valorativo de una prueba pericial contable en el ámbito del derecho tributario, pues ello permitirá dictar las pautas de integración del sentido de convicción que se genere en el intérprete de la norma tributaria debatida, además de evidenciar que, los principales argumentos que utilizan los juzgadores para desestimar un juicio de valoración pleno, carecen de sustento lógico y jurídico.

\section{PROBLEMÁTICA EN GENERAL}

Tomando en consideración que la aplicación del juicio valorativo habrá de llevarse a cabo en sede jurisdiccional para efectos del presente texto, debe acudirse

Federación (artículos 69-C a 69-H) en la que se postuló la inclusión de los métodos alternativos de solución de controversias en materia tributaria. Cfr. Comisiones unidas de hacienda y crédito público y de estudios legislativos. Senado de la República, 2013.

3

(Pérez de Ayala \& González García, 1994). 
a la aplicación del artículo 46, fracción III, de la Ley Federal de Procedimiento Contencioso $^{4}$ y del alcance que expresiones como "sana crítica" conllevan en la actualidad en torno al juicio valorativo y consecuente elemento de convicción generado en el intérprete de la norma tributaria.

Es así como surge la disyuntiva de sostener si los peritajes periciales rendidos en juicio, conforme a la práctica jurisdiccional ordinaria, deben ser desestimados bajo un razonamiento laxo, carente de vinculación jurídica y dotado de plena subjetividad por parte del intérprete de la norma, o si, por el contrario, esos extremos en materia fiscal no pueden satisfacerse dada la alta especialidad de la materia.

Bajo el primer postulado el intérprete de la norma tributaria, como regla general utiliza argumentos que desestiman un dictamen pericial observando, a su parecer, que éstos presentan como principales vicios de convicción los siguientes:

1. El perito reproduce las mismas afirmaciones que su oferente;

2. Se trata de análisis de cuestiones de carácter económico con lo cual la pericial en materia de contaduría pública no resultó la idónea para conocer a fondo y en su caso demostrar la pretensión deducida en juicio.

3. Los dictámenes son genéricos e insuficientes.

4. El dictamen pericial representa una interpretación de las normas jurídicas con lo cual se desestima por sí solo; entre otros.

Ante ello, es claro que la importancia de fijar correctamente las pautas de aplicación e interpretación en este rubro han trascendido ya al grado de cuestionar la objetividad del perito respectivo, lo cual, guarda una franca colisión, no solo con la ética de un profesional que actúa como auxiliar de la administración de justicia, sino con la oportunidad de cuestionar si existe posibilidad de albergar la construcción teórica y razonada que sustente esas afirmaciones por parte del intérprete de la norma tributaria.

Recientemente, el Poder Judicial de la Federación a través del máximo tribunal constitucional del país, ha emitido un pronunciamiento en torno a la aplicación del principio ontológico de la prueba pericial que parte de una presunción iuris tantum en el sentido apuntado en el párrafo inmediato anterior, sosteniendo que si bien es cierto que la citada presunción por su propia naturaleza puede admitir prueba en contrario, ${ }^{6}$ también fortalece la premisa de que todo peritaje se emite y funge bajo una vertiente de auxilio de la administración de justicia, por versar precisamente sobre cuestiones técnicas que escapan al común denominador del intérprete de la norma, dada la alta especialidad que requiere el objeto o materia del debate que es sometido a su consideración.

4 Artículo 46. La valoración de las pruebas se hará de acuerdo con las siguientes disposiciones:

III. El valor de las pruebas pericial y testimonial, así como el de las demás pruebas, quedará a la prudente apreciación de la sala.

5 Sobre el particular algunos autores señalan que el concepto sana crítica involucra un término complejos al procesalista y al jurista en general demás de ser un concepto muy familiar al juez que debe valorar las pruebas siguiendo mayoritariamente el sistema de las reglas de la sana crítica. (Abel Lluch, 2015).

6 Caso contrario estaríamos en presencia de una presunción del tipo iure et de iure. 
La motivación que tienen las partes en el juicio al ofrecer una probanza, se traduce en el interés que éstas tienen de aportar un elemento para corroborar la veracidad de los elementos fundatorios de sus pretensiones, por lo cual, tratándose de la prueba pericial, su utilidad consiste en que la información experta que se allegue al procedimiento sea aprovechable y útil para el juzgador, además de ser pertinente respecto de la controversia.

Sin embargo, ni en la Ley Federal de Procedimiento Contencioso Administrativo, ni en el Código Federal de Procedimientos Civiles como ordenamiento jurídico supletorio a dichas legislaciones, se prevén las prescripciones necesarias para regular la forma en que éste medio de prueba habrá de evaluarse ante los "paradigmas" antes sintetizados.

Para que una prueba pericial pueda cumplir su objetivo dentro de un proceso, esto es, proporcionar al resolutor la información que le permita contar con explicaciones necesarias para tomar una resolución que involucre conocimientos especializados propios de una ciencia, técnica o arte, es preciso que al realizarse su ofrecimiento, se indique el objeto del dictamen y que en los casos en que resulte necesario, se establezcan las referencias de hecho que el perito debe tomar en consideración para cumplir con esa meta.

En esta medida, es claro que estos aspectos se satisfacen desde el ofrecimiento de la prueba misma en materia fiscal, pues el extremo anunciado debe satisfacerse desde el ofrecimiento de la prueba en términos del artículo 14, fracción V, de la Ley Federal de Procedimiento Contencioso Administrativo. ${ }^{7}$

De ahí que, si para la prueba pericial es necesaria la demarcación de los aspectos de hecho a partir de los cuales el perito habrá de emitir su opinión desde que se realizó su ofrecimiento, es claro que esa condición es satisfecha por mandato expreso de la propia ley del procedimiento.

Aunado a lo anterior, los artículos 15, fracción VII ${ }^{8}$ y 43 de la Ley Federal de Procedimiento Contencioso Administrativo, ${ }^{9}$ en directa relación con los artículos

$7 \quad$ Así lo establece el artículo de referencia de la siguiente manera:

"Artículo 14. La demanda deberá indicar: ...

V. Las pruebas que ofrezca.

En caso de que se ofrezca prueba pericial o testimonial se precisarán los hechos sobre los que deban versar y señalarán los nombres y domicilios del perito o de los testigos."

8 Artículo 15. El demandante deberá adjuntar a su demanda: ...

VII. El cuestionario que debe desahogar el perito, el cual deberá ir firmado por el demandante.

9 Artículo 43. La prueba pericial se sujetará a lo siguiente:

I. En el acuerdo que recaiga a la contestación de la demanda o de su ampliación, se requerirá a las partes para que dentro del plazo de diez días presenten a sus peritos, a fin de que acrediten que reúnen los requisitos correspondientes, acepten el cargo y protesten su legal desempeño, apercibiéndolas de que si no lo hacen sin justa causa, o la persona propuesta no acepta el cargo o no reúne los requisitos de ley, sólo se considerará el peritaje de quien haya cumplimentado el requerimiento.

Los peritos deberán rendir su propio dictamen autónomo e independiente y exponer sus razones o sustentos en los que se apoyan, por lo que no deberán sustentar su dictamen en las respuestas expuestas por otro perito, ni remitirse a ellas para justificar su opinión técnica.

II. El magistrado instructor, cuando a su juicio deba presidir la diligencia y lo permita la naturaleza de ésta, señalará lugar, día y hora para el desahogo de la prueba pericial, pudiendo pedir a los peritos todas las aclaraciones que estime conducentes, y exigirles la práctica de nuevas diligencias. 

de la prueba pericial queda a la prudente apreciación del tribunal, no configuran de ninguna manera una facultad omnímoda, ni mucho menos discrecional en favor del intérprete de la norma.

Por el contrario, estas hipótesis normativas hacen necesario que, ante la presentación de dictámenes científicos o técnicos expertos, el juzgador deba determinar, previamente, si los razonamientos subyacentes en ellos y la metodología ahí empleada son científica o técnicamente válidos y si pueden aplicarse a los hechos que son sujetos a demostrarse.

Así, la calificación de confiabilidad del dictamen dependerá directamente del enfoque que adopte el juzgador, el cual además de determinarse por los principios y metodología empleados, también se determinan por el objeto de la prueba pericial, de la litis efectivamente deducida en juicio y por aspectos prácticos de razonabilidad, sin que en modo alguno esa calificación deba obedecer a la parte oferente de dicha prueba. ${ }^{12}$

III. En los acuerdos por los que se discierna del cargo a cada perito, el magistrado instructor concederá un plazo mínimo de quince días para que rinda y ratifique su dictamen, con el apercibimiento a la parte que lo propuso de que únicamente se considerarán los dictámenes rendidos dentro del plazo concedido.

IV. Por una sola vez y por causa que lo justifique, comunicada al instructor antes de vencer los plazos mencionados en este artículo, las partes podrán solicitar la ampliación del plazo para rendir el dictamen o la sustitución de su perito, señalando en éste caso, el nombre y domicilio de la nueva persona propuesta. La parte que haya sustituido a su perito conforme a la fracción I, ya no podrá hacerlo en el caso previsto en la fracción III de este precepto.

V. El perito tercero será designado por la Sala Regional de entre los que tenga adscritos. En el caso de que no hubiere perito adscrito en la ciencia o arte sobre el cual verse el peritaje, la Sala designará bajo su responsabilidad a la persona que deba rendir dicho dictamen. Cuando haya lugar a designar perito tercero valuador, el nombramiento deberá recaer en una institución de crédito, debiendo cubrirse sus honorarios por las partes. En los demás casos los cubrirá el Tribunal. En el auto en que se designe perito tercero, se le concederá un plazo mínimo de quince días para que rinda su dictamen.

El Magistrado Instructor, dentro del plazo de tres días posteriores a la notificación del acuerdo que tenga por rendido el dictamen del perito tercero, podrá ordenar que se lleve a cabo el desahogo de una junta de peritos, en la cual se planteen aclaraciones en relación a los dictámenes. El acuerdo por el que se fije el lugar, día y hora para la celebración de la junta de peritos deberá notificarse a todas las partes, así como a los peritos.

En la audiencia, el Magistrado Instructor podrá requerir que los peritos hagan las aclaraciones correspondientes, debiendo levantar el acta circunstanciada correspondiente.

En el caso de la Sala Superior del Tribunal, el Magistrado ponente podrá ordenar directamente la reapertura de la instrucción del juicio, a efecto de que la junta de peritos se realice en la Secretaría General o Adjunta de Acuerdos o en la Sala Regional, la cual podrá llevarse a cabo a través de medios electrónicos.

10 Artículo 197. El tribunal goza de la más amplia libertad para hacer el análisis de las pruebas rendidas; para determinar el valor de las mismas, unas enfrente de las otras, y para fijar el resultado final de dicha valuación contradictoria; a no ser que la ley fije las reglas para hacer esta valuación, observando, sin embargo, respecto de cada especie de prueba, lo dispuesto en este capítulo. Artículo 211. El valor de la prueba pericial quedará a la prudente apreciación del tribunal.

Al respecto el Poder Judicial ha establecido como estándares para la prueba pericial en materia de amparo que "la motivación que tienen las partes en el juicio al ofrecer una probanza es que les reporte un elemento de corroboración de la veracidad de los enunciados sobre los hechos fundatorios de sus pretensiones o de sus defensas, respectivamente y, tratándose de la prueba pericial, su utilidad consiste en que la información experta que se allegue al procedimiento sea aprovechable para el juzgador, debe ser pertinente respecto de la controversia y relevante en aspectos especializados específicos. Por su parte, de las disposiciones normativas que en materia de pruebas consigna la Ley de Amparo, en su artículo 119 se establece la relativa a la forma 
En ese sentido, se postulan como criterios para admitir o excluir las pruebas periciales de contenido científico o técnico, o bien, algunos aspectos específicos de éstas, a circunstancias tales como:

a) la teoría en la que se fundamentan;

b) el porcentaje de error conocido o potencial, así como el cumplimiento de los estándares correspondientes a la técnica empleada;

c) las publicaciones de la teoría o la técnica que hubieren sido sometidas al control de otros expertos; $y$,

d) la existencia de un consenso general de la comunidad científica o técnica interesada.

\section{DETERMINACIÓN EN LA CALIFICACIÓN DE LA PRUEBA PERICIAL COMO MEDIO PROBATORIO EFICAZ EN MATERIA TRIBUTARIA}

En la mayoría de los asuntos tributarios, de manera cauta puede sostenerse que, cuando se advierte el ofrecimiento de una prueba pericial contable toda regla de lógica, sana crítica y razonabilidad, apuntan a discernir si la aplicación concreta y real de los valores que fueron individualizados en la esfera jurídica del contribuyente respetaron o no las reglas contenidas en la legislación tributaria.

Esto en modo alguno puede representar o significar que el auxiliar de la administración de justicia, éste sosteniendo una interpretación jurídica. Por el contrario, la referencia que se haga a las disposiciones tributarias como normas jurídicas, se delimita porque es precisamente en esas normas en donde se debe establecer la mecánica de cálculo de esos valores económicos que pretenden ser individualizados en la esfera jurídica del contribuyente.

En tal medida, si los vicios propios de ilegalidad atribuidos a los valores que fueron individualizados se cuestionaron a través del denominado juicio de nulidad, precisamente porque a través del mismo se atribuyeron vicios de legalidad en su

en la que debe ofrecerse la prueba pericial, y dispone que se hará presentando el cuestionario que, una vez calificado, habrá de responder el perito; sin embargo, en dicha ley ni en su ordenamiento supletorio, el Código Federal de Procedimientos Civiles, se prevén las prescripciones necesarias para regular la forma en que este medio de prueba habrá de evaluarse, lo que hace necesario recurrir a las máximas de la experiencia para su complementación, que se basan en aspectos prácticos de razonabilidad. De acuerdo con lo anterior, para que una prueba pericial pueda cumplir su objetivo dentro de un proceso, de proporcionar al resolutor información que le permita contar con explicaciones necesarias para tomar decisiones que involucren conocimientos especializados, propios de una ciencia, técnica o arte, es preciso que al realizarse su ofrecimiento se indique el objeto del dictamen y que, en los casos en que resulte necesario, se establezcan las referencias de hecho que el perito debe tomar en consideración, ya sea porque se encuentren reconocidas o aceptadas. De no realizarse esa delimitación del contexto en que ha de producirse la peritación, se corre el riesgo de que no haya control sobre los elementos de hecho que el perito puede tomar en consideración e, incluso, que sea utilizado para tratar de introducir al proceso probanzas de naturaleza diversa. De ahí que, si para la prueba pericial es necesaria la demarcación de los aspectos de hecho a partir de los cuales el perito habrá de emitir su opinión, al realizarse su ofrecimiento debe cumplirse esa condición pues, de lo contrario, el dictamen obtenido resultará ineficaz." ( $C f r$ r. tesis I.1o.A.E.66 K, Semanario Judicial de la Federación y su Gaceta, décima época, tomo IV, octubre de 2016). 
conformación, es claro "y lógico" sostener que, la prueba pericial concreta aporta un elemento de convicción para explicar fenómenos complejos con efectos técnicos, que escapan al entendimiento de la actividad habitual desarrollada por la sala fiscal. En consecuencia, dicha prueba, "por lógica", resulta una prueba idónea y oportuna para conocer "a fondo" la incidencia de los vicios de ilegalidad debatidos.

Debe realizarse un particular énfasis en que, cuando un valor es individualizado en la esfera jurídica del contribuyente, esto genera una afectación económica por sí sola.

En consecuencia, al ser la contabilidad una técnica que sistemática y estructuralmente produce información cuantitativa expresada en unidades monetarias sobre las situaciones económicas identificables que realiza un contribuyente, es claro que, la eficacia ${ }^{13}$ de dicha prueba es un medio de convicción idóneo para acreditar una pretensión en ese sentido, pues a través del contenido de sus dictámenes se identifica la situación individualizada del gobernado en torno a un requerimiento de pago específico.

Es necesario señalar que la contabilidad se aboca a la captación de las operaciones efectuadas por una entidad, las cuales son analizadas, clasificadas y registradas para generar información concreta, en consecuencia, la prueba pericial en materia contable sí constituye un medio probatorio idóneo para acreditar hechos presentes y ciertos, pues ante un acto de liquidación, la respuesta del perito sobre la forma en que aquél se constituyó produce información cuantitativa expresada sobre las situaciones identificables y cuantificables, lo que implica que la referida pericial, arroje elementos objetivos que deben generar convicción en el juzgador. ${ }^{14}$

En este mismo sentido, si el objeto de la prueba pericial es el auxilio en la administración de justicia, mismo que consiste en permitir que un experto en determinada ciencia, técnica o arte, aporte al juzgador conocimientos propios de su pericia y de los que el juzgador carece, porque escapan al cúmulo de los que posee una persona de nivel cultural promedio, los cuales, además, resultan esenciales para resolver determinada controversia, luego, es claro que el uso de la pericial y con ella de los métodos científicos que la misma involucra, implican el aprovechamiento de conocimientos especializados indispensables para apreciar y calificar ciertos hechos o evidencias susceptibles de atribuirles o negarles un sig-

13 Sobre el tema la doctrina internacional en otras materias afines al juicio de valor de la prueba pericial ha sostenido que “...lo más relevante a los efectos de imprimir validez a una prueba pericial es la existencia de mecanismos que permitan a las partes y al Tribunal Arbitral poner en entredicho las manifestaciones vertidas por los peritos." (Jiménez Blanco \& Pujol, 2016).

14 Al respecto el Poder Judicial ha establecido que “... la eficacia probatoria de los dictámenes periciales dependerá de que logren aportar al juzgador información sobre reglas, principios, criterios, interpretaciones o calificaciones de circunstancias, argumentos o razones para la formación de su convencimiento, ajenos al derecho y pertinentes a disciplinas científicas, tecnológicas o artísticas, preferentemente, respecto de ciertos hechos o prácticas, también especiales, cuya percepción o entendimiento escapa a las aptitudes del común de la gente y requieren esa capacidad particular para su adecuada percepción y la correcta verificación de sus relaciones con otros hechos, de sus causas y efectos o, simplemente, para su apreciación e interpretación." (Cfr. tesis I.1o.A.E.148 A, Semanario Judicial de la Federación y su Gaceta, décima época, tomo IV, mayo de 2016, p. 2837). 
nificado respecto a una aplicación concreta, con lo cual esa información resulta útil para determinar qué circunstancias o evidencias son necesarias, conforme al marco metodológico, para arribar válidamente a la conclusión sostenida en los mismos. ${ }^{15}$

En esa medida, la calificación de esos hechos y la atribución de ese significado respecto de la aplicación concreta de la prueba, en ningún momento permite cuestionar la respuesta de un dictamen pericial dependiendo de quien haya sido su oferente, pues se insiste, la perspectiva de su valoración e interpretación depende en todo momento de ponderar que el objeto de la prueba pericial es el auxilio en la administración de justicia, no de cuestionar la ética e integridad profesional del perito dependiendo de la parte que se hubiera configurado como su oferente.

De esta forma, tanto las evidencias, como los métodos involucrados en ese proceso deben ser relevantes y fiables para el resultado, fin o propósito que el medio probatorio pretenda alcanzar; aspectos que deben tomarse en cuenta para la calificación de la prueba en lo relativo a su pertinencia e idoneidad, sin ponderar en su juicio de valor quien es el oferente de la prueba.

Por razones lógico-jurídicas, la prueba pericial prevista en el capítulo IV del título cuarto del libro primero del Código Federal de Procedimientos Civiles, de aplicación supletoria al juicio contencioso administrativo federal, se desdobla en su ejecución a través de los dictámenes de los peritos estableciendo que éstos deben colmar los requisitos de fondo siguientes:

a) Contener la información empleada para sustentar el análisis del experto;

b) Consignar la metodología utilizada que describa los procedimientos y elementos técnicos, científicos o artísticos, empleados para llevar a cabo el examen de las cuestiones sometidas a su calificación y, en su caso, hagan referencia a los principios, máximas de la experiencia o conocimientos especializados que se apliquen;

c) Señalar las razones o elementos en consideración para orientar las conclusiones o las opiniones preferentes si hay diversidad de opciones elegibles;

d) Referir que el conocimiento científico o técnico aportado sea directamente relevante y concretamente útil para el negocio; y,

e) Formular conclusiones claras, firmes y congruentes con su análisis. ${ }^{16}$

15 Al respecto el Poder Judicial ha establecido que “... el uso, primordialmente, de la pericial, y con ella de los métodos científicos, implica el aprovechamiento de conocimientos especializados, indispensables para apreciar y calificar ciertos hechos o evidencias y poderles atribuir o negar significado respecto a una cierta práctica, hipótesis o conjetura que pretende acreditarse. También es útil para determinar qué circunstancias o evidencias son necesarias, conforme al marco metodológico, para arribar válidamente a cierta conclusión. De esta forma, tanto las evidencias, como los métodos deben ser relevantes y fiables para el resultado, fin o propósito que con el medio probatorio se intente alcanzar; aspectos que deben tomarse en cuenta para la calificación de la prueba en lo relativo a su pertinencia e idoneidad..." (Cfr. tesis I.1o.A.E.45 K (10a.), Semanario Judicial de la Federación y su Gaceta, décima época, tomo IV, noviembre de 2015, p. 3605).

16 (Cfr. tesis I.1o.A.E.147 A (10a.), Semanario Judicial de la Federación y su Gaceta, décima época, tomo IV, mayo de 2016, p. 2838). 
En esta tesitura, resulta claro que la prueba pericial, al ser científica, proporciona al órgano jurisdiccional elementos de naturaleza técnica que le permiten entender, calificar e interpretar ciertos hechos cuya intelección exige conocimientos técnicos de determinadas disciplinas con los que no cuenta la sala fiscal y por ende, la misma debe de acudir a aquellas figuras que se configuran como auxiliares de la administración de justicia, para allegarse de esa información y resolver en consecuencia.

\section{PRINCIPIO DE IMPARCIALIDAD DEL PERITO COMO PRESUNCIÓN IURIS TANTUM}

Es así como en atención al marco teórico anterior, debe iniciarse ahora con la elaboración de esta parte argumentativa estableciendo la consideración de que, tanto la doctrina como la práctica forense, convergen en torno al tema de la valoración de las pruebas señalando que existen los sistemas tasado (o legal) y el sistema de pruebas libres (o de libre convicción). ${ }^{17}$

Por un lado, el sistema tasado es aquel en el que la ley señala por anticipado la eficacia probatoria que el juzgador debe atribuir a cada probanza, mientras que, el sistema de libre convicción, es aquel que se funda en la sana crítica que constituyen las reglas del correcto entendimiento humano, en las cuales interfieren las reglas de la lógica con las reglas de la experiencia del juzgador, contribuyendo a que pueda analizar la prueba con arreglo a la sana razón y a un conocimiento experimental de las cosas. ${ }^{18}$

Por cuanto hace al caso concreto, los principios relativos a la valoración de la prueba según el sistema de libre convicción, se encuentran previstos en el artículo 197 del Código Federal de Procedimientos Civiles, al establecer que los medios de prueba aportados y admitidos, serán valorados en su conjunto por el juzgador, de modo que, salvo aquellos casos en que la ley otorga el valor probatorio a una prueba, el juez debe decidir con arreglo a la sana crítica, esto es, sin razonar a voluntad, discrecionalmente o arbitrariamente.

En este sentido, si el peritaje es una actividad humana de carácter procesal, desarrollada en virtud de encargo judicial por personas distintas de las partes del proceso, especialmente calificadas. por su experiencia o conocimientos técnicos, artísticos o científicos y mediante la cual se suministran al juzgador argumentos y razones para la formación de su convencimiento respecto de ciertos hechos, también especiales, cuya percepción y entendimiento escapa a las aptitudes del común de las personas y requieren esa capacidad particular para su adecuada percepción y la correcta verificación de sus relaciones con otros hechos, de sus causas y de sus efectos o, simplemente, para su apreciación e interpretación, es claro que la peritación cumple con una doble función: verificar los hechos que requieren conocimientos técnicos, artísticos o científicos que escapan a la cultura común del juez; y dos, suministrar reglas técnicas o científicas de la experiencia

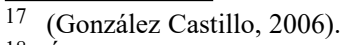

18 Ídem. 
especializada de los peritos para formar la convicción del juez sobre tales hechos ilustrando su entendimiento.

En tal virtud, el valor probatorio del peritaje radica en una presunción concreta, de que el perito es sincero, veraz, honesto, imparcial, capaz y experto en la materia sobre la cual dictamina, en la que además ha estudiado cuidadosamente el problema sometido a su consideración y ha emitido su concepto sobre tales percepciones y las deducciones que de ellas se concluyen, gracias a las reglas técnicas, científicas ${ }^{19}$ o artísticas de la experiencia que conoce y aplica para esos fines, en forma explicada, motivada, fundada y conveniente.

Ante ello, es ilegal desestimar una opinión pericial, el hecho de que se trata de análisis de cuestiones de carácter económico con lo cual la pericial en materia de contaduría pública no resulte idónea para conocer el fondo debatido y en su caso demostrar la pretensión deducida en juicio; ni tampoco para sostener que los dictámenes son genéricos e insuficientes; ni que el dictamen pericial representa una interpretación de las normas jurídicas lo que hace que el mismo se desestime por sí solo; o bien, que el perito reproduce las mismas afirmaciones que su oferente; etcétera.

Y es que la trascendencia de dicha determinación vincula a los artículos 15 , fracción VII y 43 de la Ley Federal de Procedimiento Contencioso Administrativo, en directa relación con los artículos 197 y 211 del Código Federal de Procedimientos Civiles, pues a partir de ellos se hace necesario que, ante la presentación de dictámenes científicos o técnicos expertos, el juzgador deba determinar si los razonamientos subyacentes en ellos y la metodología ahí empleada son científica o técnicamente válidos y si pueden aplicarse a los hechos sujetos a demostración; aspectos que nada tienen que ver si el peritaje es ofrecido por alguna de las partes contendientes.

Por tanto, no resulta apegado a derecho negar todo valor probatorio a los dictámenes de referencia por el solo hecho de que la sala fiscal considere que cuenta con una facultad omnímoda de "libre valoración", sino que, incluso existe la obligación de que, su criterio deben considerar dichos dictámenes incluso como un indicio y por tanto debe atender los hechos que con ellas se pretende probar en su integración con el resto de los elementos probatorios que hayan sido ofrecidos, a fin de establecer como resultado una valuación integral de todas las pruebas ofrecidas y con ello fijar un verdadero alcance del caudal probatorio con el que cuente el intérprete de la norma tributaria.

En esta tesitura, no solo era de esperarse el pronunciamiento vertido por la Primera Sala de la Suprema Corte de Justicia de la Nación en el que ha reconocido que el objeto de la prueba pericial es auxiliar al juzgador en la evaluación de hechos o circunstancias que requieren conocimientos técnicos y especializados

19 Para el caso de la actuación del perito contable éste se basa en el boletín 7010 "Normas para Atestiguar" en correlación con el boletín 7050 “Otros Informes sobre exámenes y Revisiones de atestiguamiento", emitidos por el Instituto Mexicano de Contadores Públicos, A.C., así como de la NIF A-2, como requisitos de fondo que debe contener un dictamen para ser valorado plenamente y crear convicción en el órgano resolutor. (Instituto Mexicano de Contadores Públicos, 2005). 
de los cuales carece, por lo que se estima que los peritos actúan como verdaderos auxiliares en la administración de justicia y no con tintes de "sociedad" de la parte oferente de la prueba.

Bajo este postulado, se ordenó que el desempeño de su encargo debe regirse por el principio de imparcialidad, el cual los obliga a permanecer ajenos a los intereses de las partes en controversia, aun cuando éstas los hubieran designado, pues su actuación debe contribuir a resolver el juicio sin favorecer indebidamente a las partes, siendo que, bajo esos postulados, existe la presunción de que los peritos actúan de forma imparcial iuris tantum de que opera el principio de imparcialidad.

$\mathrm{Y}$ en un segundo orden, puede válidamente sostenerse que atento a ese parámetro de valoración de atender a una sana crítica, resulta indispensable traer a colación la trascendencia de que, un dictamen contable, por la misma estructura de nuestro sistema legal, "curiosamente" es valorado a partir de presunciones de derecho, con lo cual, la afirmación tajante del intérprete de la norma tributaria en el sentido de que son cuestiones de carácter económico, o sus conclusiones deben ser desestimadas cunado representan una interpretación de las normas jurídicas, se desestiman por sí solas.

En reconocimiento a estos postulados dentro del orden jurídico que impera la interpretación de la materia tributaria, puede válidamente armonizarse el contenido de la tesis aislada emitida por la Primera Sala del Alto tribunal siguiente mismo que fuera publicado en el Semanario Judicial de la Federación correspondiente:

PERITOS. EL DESEMPEÑO DE SU ENCARGO DEBE REGIRSE POR EL PRINCIPIO DE IMPARCIALIDAD, AUN TRATÁNDOSE DE LOS DESIGNADOS POR LAS PARTES. La Primera Sala de la Suprema Corte de Justicia de la Nación ha reconocido que el objeto de la prueba pericial es auxiliar al juzgador en la evaluación de hechos o circunstancias que requieren conocimientos técnicos y especializados de los cuales carece, por lo que se ha estimado que los peritos actúan como verdaderos auxiliares en la administración de justicia, pues a través de sus conocimientos hacen posible el ejercicio de la labor jurisdiccional al permitir al Juez dirimir la controversia sometida a su conocimiento; de ahí que el desempeño de su encargo debe regirse por el principio de imparcialidad, el cual los obliga a permanecer ajenos a los intereses de las partes en controversia, aun cuando éstas los hubieran designado, pues su actuación debe contribuir a resolver el juicio sin favorecerlas indebidamente. Ahora bien, del análisis de los preceptos que regulan la prueba pericial en el Código de Procedimientos Civiles para el Distrito Federal, aplicable para la Ciudad de México, se advierte que respecto de los peritos designados por las partes, a pesar de esta circunstancia y de que son ellas quienes en principio cubren sus honorarios, existe la presunción de que los peritos actúan de forma imparcial; sin embargo, dicha presunción admite prueba en contrario, por lo que ante el reclamo de alguna de las partes en el sentido de que alguno de los peritos se ha conducido con parcialidad, el Juez debe evaluar el desempeño de la función auxiliar encomendada, analizando los diversos elementos que concurren en el caso para determinar si la presunción iuris tantum ha quedado desvirtuada, y tomando en cuenta que la carga de la prueba corresponde a quien alega que el principio de imparcialidad no fue respetado. ${ }^{20}$

$\overline{20}$ Tesis 1a. XXIX/2018, Semanario Judicial de la Federación y su Gaceta, décima época, marzo de 2018. 
En este sentido, se establece finalmente que es a partir de estos postulados que el intérprete de la norma tributaria debe justipreciar las cuestiones técnicas controvertidas, por esa precisa razón, es decir, por tratarse de cuestiones técnicas que en ningún momento pueden dejar margen a la discrecionalidad, ni del oferente, ni del auxiliar de la administración de justicia, ni mucho menos, del intérprete de la norma tributaria.

\section{CONCLUSIONES}

Primera. La prueba pericial contable en materia fiscal debe precisar su utilidad, eficacia e idoneidad a partir de su concepción como un instrumento ejecutado por auxiliares de la administración de justicia en estricto sentido.

Segunda. Bajo una perspectiva de que los peritos se configuran como auténticos auxiliares de la administración de justicia, el intérprete de la norma se coloca en una situación que le permite armonizar todo el caudal probatorio con el que cuenta para resolver las cuestiones técnicas que son sometidas a su consideración excluyendo por sí sola una valoración aislada del dictamen pericial contable.

Tercera. Nuestro sistema legal ha comenzado a destacar un sistema de valoración basado en presunciones jurídicas sobre cuestiones de carácter técnico propias o inherentes a una disciplina distinta del derecho que, por un lado, permite ya armonizar el sentido de la decisión final del intérprete de la norma con la técnica o conocimiento que se requiere para resolver la cuestión debatida; y por el otro, permite generar un mecanismo que evita la interdicción en la arbitrariedad de la interpretación de la norma bajo paradigmas subjetivos con los que hasta ahora cuenta el juez.

\section{REFERENCIAS}

ABEL LLUCH, X. (2015). Las regas de la sana crítica. La Ley.

ARRIETA MARTÍNEZ DE PISÓN, J. (2008). Derecho tributario y medios alternativos de solución de controversias (Vol. 11). (F. d. (AFDUAM), Ed.) España.

Australian tax office. (2009). Practice statement law administration 2009/9, Conduct of tax office litigation. Australia: Australian tax office.

BOTELLA GARCÍA-LASTRA, C. (1996). La finalización convencional de los procedimientos tributarios y otras técnicas transaccionales para la resolución de conflictos. En G. E. Pisarik, Convención y arbitraje en el Derecho Tributario. Madrid: Marcial Pons-IEF.

Comisiones unidas de hacienda y crédito público y de estudios legislativos. Senado de la República. (2013). Dictamen correspondiente a la minuta con proyecto de decreto por el que se reforman, adicionan y derogan diversas disposiciones del Código Fiscal de la Federación. México: Senado de la República. 
GONZÁLEZ CASTILLO, J. (2006). La fundamentación de las sentencias y la sana crítica. Revista Chilena de Derecho, 33(1), 93-107.

HARRISON, W., \& HORNGREN, C. (2003). Contabilidad. México: Pearson.

Instituto Mexicano de Contadores Públicos. (2005). Principios de contabilidad generalmente aceptados, (20 ed.). México: Instituto Mexicano de Contadores Públicos.

JIMÉNEZ BLANCO, G., \& PUJOL, O. (2016). Arbitraje y prueba pericial. (U. C. Uruguay, Ed.) Revista de Derecho. Publicación arbitrada de la Universidad Católica del Uruguay., 13, 33-86.

LÓPEZ CASTRO, P. (2005). Contabilidad básica. México: Éxodo.

MIRANDA CAMARENA, A., \& NAVARRO RODRÍGUEZ, P. (julio-diciembre de 2014). El principio de interpretación conforme en el derecho constitucional mexicano. (U. d. Medellín, Ed.) Opinión Jurídica-Universidad de Medellín, 13(26), 69-79.

PÉREZ , J.; SUÁREZ, H.; DÉNIZ, J., \& BONA, C. (2007). Fundamentos de contabilidad: teoría y práctica. Madrid: Delta publicaciones universitarias.

PÉREZ DE AYALA, J., \& GONZÁLEZ GARCÍA, E. (1994). Derecho tributario I. Salamanca, España: Plaza Universitaria ediciones.

POMBO, J. (2011). Contabilidad general. Madrid: Paraninfo.

Procuraduría de la Defensa del Contribuyente. (2014). La Procuraduria de la Defensa del Contribuyente, Serie de cuadernos de la Procuraduría de la Defensa del Contribuyente (Vol. XIII). México: Procuraduría de la Defensa del Contribuyente.

RAMÍREZ, J. G. (s.f.). Medios alternativos de resolución de conflictos como solución complementaria de administración de justicia. México: Suprema Corte de Justicia de a Nación.

SÁNCHEZ ACEVES, J. (2008). La creación de una instancia de conciliación en materia tributaria previa al juicio de nulidad fiscal. Letras jurídicas: Revita electrónica de derecho(6).

TROYA JARAMILLO, J. V. (2004). Los medios alternativos de solución de conflictos y el derecho tributario internacional. (U. A. Bolivar, Ed.) Foro Revista de $\operatorname{Derecho(3).}$ 